\title{
Low serum calcium is associated with perioperative blood loss and transfusion rate in elderly patients with hip fracture: a retrospective study
}

\author{
Zhicong Wang ${ }^{\dagger}, X_{i}$ Chen ${ }^{\dagger}$, Yan Chen ${ }^{\dagger}$, Ling Yang, Hong Wang, Wei Jiang, Shuping Liu* and Yuehong Liu*
}

\begin{abstract}
Background: To investigate whether hypocalcemia influenced total blood loss and transfusion rate in elderly patients with hip fracture.

Methods: From our hip fracture database, patients were consecutively included between January 2014 and December 2020. Serum calcium level was corrected for albumin concentration, and hypocalcaemia was defined as corrected calcium $<2.11 \mathrm{mmol} / \mathrm{L}$. Hemoglobin and hematocrit were obtained on admission day and postoperative day, and blood transfusions were collected. According to the combination formulas of Nadler and Gross, the total blood loss of each patient was calculated. Risk factors were further analyzed by multivariate linear regression.

Results: A total of 583 consecutive elderly hip fracture patients were finally included (mean age $79.32 \pm 8.18$ years, $68.61 \%$ female). On admission, the mean serum corrected calcium level was $2.17 \pm 0.14 \mathrm{mmol} / \mathrm{L}$, and the prevalence of hypocalcemia was $33.11 \%$ (95\% Cl: 29.42-37.02). When comparing patients with normal calcium, hypocalcemia patients exhibited a higher blood transfusion rate $(7.69 \%$ vs $16.06 \%, P<0.05)$, and significantly larger total blood loss $(607.86 \pm 497.07 \mathrm{ml}$ vs $719.18 \pm 569.98 \mathrm{ml}, P<0.05)$. Multivariate linear regression analysis showed that male, anemia on admission, time from injury to hospital, intertrochanteric fracture, blood transfusion and hypocalcemia were independently associated with increased total blood loss $(P<0.05)$.
\end{abstract}

Conclusion: Hypocalcemia is common in elderly patients with hip fracture, and significantly associated with more total blood loss and blood transfusion. The other risk factors for increased total blood loss are male, anemia on admission, time from injury to hospital, intertrochanteric fracture, and blood transfusion.

Level of evidence: Level III, retrospective study.

Keywords: Hypocalcemia, Hip fracture, Elderly, Blood loss, Blood transfusion

*Correspondence: doctorliushuping@126.com; doctorliuyuehong@163.com †Zhicong Wang, Xi Chen and Yan Chen contributed equally to this work. Department of Orthopedic Surgery, Deyang People's Hospital,

Orthopaedic Center of Deyang City, Deyang 618000, Sichuan, China

\begin{abstract}
Background
With an increasing aging population, hip fractures become a major public health issue, along with high morbidity, disability, mortality, and social costs $[1,2]$. Even more, it is estimated that there will be 4.5 million hip fractures worldwide by the year 2050, and 1.3 million cases will be in China [3, 4]. After the initial injury, hip fracture patients may suffer from a large amount of total
\end{abstract} permits use, sharing, adaptation, distribution and reproduction in any medium or format, as long as you give appropriate credit to the original author(s) and the source, provide a link to the Creative Commons licence, and indicate if changes were made. The images or other third party material in this article are included in the article's Creative Commons licence, unless indicated otherwise in a credit line to the material. If material is not included in the article's Creative Commons licence and your intended use is not permitted by statutory regulation or exceeds the permitted use, you will need to obtain permission directly from the copyright holder. To view a copy of this licence, visit http://creativecommons.org/licenses/by/4.0/. The Creative Commons Public Domain Dedication waiver (http://creativeco mmons.org/publicdomain/zero/1.0/) applies to the data made available in this article, unless otherwise stated in a credit line to the data. 
blood loss, which vary from $859 \mathrm{ml}$ to $1208 \mathrm{ml}$ in patients with femur neck fracture [5-7], and $406 \mathrm{ml}$ to $1269 \mathrm{ml}$ in patients with intertrochanteric fracture [6, 8-11]. Similarly, a prospective study found that the blood loss can reach up to $1013 \mathrm{ml}$ even prior to the surgery [12].

Blood loss in elderly patients makes them prone to perioperative anemia due to the presence of comorbidities and limited physiological reserve [6]. Recently, an increasing number of studies have confirmed that low hemoglobin or anemia on admission was significantly associated with increased mortality, postoperative complications, and poorer physical function [13-15]. As we known, blood transfusion is the most commonly used intervention to correct anemia, but causes more adverse events in elderly patients [16].

Serum calcium as the coagulation factor IV, participates in the regulation of coagulation cascade [17]. Hypocalcemia is a common electrolyte disorder in hospitalized patients, nearly $56.2 \%$ in trauma patients [18]. Many studies have already investigated its harmful effect, and found that hypocalcemia was associated with more bleeding or blood transfusion in patients with intracerebral hemorrhage [19], postpartum hemorrhage [20], upper gastrointestinal bleeding [21], shocked trauma [22], and total knee arthroplasty [23].

Several studies indicated that the prevalence of hypocalcemia was common in elderly orthopedic patients [23-25]. For this reason, we hypothesized that low serum calcium on admission may led to more perioperative blood loss. To our knowledge, there is no available literature regarding this issue in hip fracture patients undergoing surgery. Therefore, we aimed to close this gap and investigate whether serum calcium influenced total blood loss and transfusion rate in these patients.

\section{Methods}

\section{Study design and population}

We performed a retrospective study using data from our hip fracture database, which has been described in detail previously [26]. From January 2014 to December 2020, patients were enrolled consecutively into the database when the following criteria were met: (1) confirmed diagnosis of hip fracture, but not pathological fracture; (2) age $\geq 60$ years; (3) caused by low-energy fall from a standing height or less; (4) fresh fracture less than 3 weeks. In this study, patients without surgical treatment $(n=327)$, blood routine test within postoperative 3 days $(n=115)$, as well as admission calcium, hemoglobin $(\mathrm{Hb})$, hematocrit (Hct) data $(n=19)$ were excluded (Fig. 1$)$. The study protocol was approved by the Institutional Ethics Committee at Deyang People's Hospital (IRD number 202104-019-K01). Permission to waive the informed consent was obtained from the institutional review board for this observational retrospective study.

\section{Data collection procedures}

The following data were extracted from this hip fracture database, including demographics (age, sex, height, weight), medical history (hypertension, diabetes mellitus), fracture information (time from injury to hospital, hip fracture type), and laboratory tests (calcium, albumin, $\mathrm{Hb}, \mathrm{Hct}$ ). Also, charlson comorbidity index (CCI) was calculated for each patient based on 17 comorbidities, and categorized as none $(\mathrm{CCI}=0)$, low $(\mathrm{CCI}=1)$, or moderate/severe $(\mathrm{CCI} \geq 2)$ [27]. Body mass index (BMI) was calculated as BMI $=$ Weight $(\mathrm{kg}) /$ Height $(\mathrm{m})^{2}$. Time from injury to hospital was defined as the interval between the injury date and the subsequent admission date. Hip fracture type was confirmed by X-ray and/ or computed tomography (CT), and then classified as femur neck or intertrochanteric fracture. According to the WHO criteria, anemia was defined as $\mathrm{Hb}<130 \mathrm{~g} / \mathrm{dl}$ for men and $<120 \mathrm{~g} / \mathrm{dl}$ for women. Owing to the influence of albumin concentration, serum calcium was corrected using the following formula: corrected calcium $=$ measured serum calcium $(\mathrm{mmol} / \mathrm{L})+0.02 \times[40.0$ - albumin $(\mathrm{g} / \mathrm{L})][28]$. Using the normal reference range in our hospital $(2.11-2.52 \mathrm{mmol} / \mathrm{L})$, hypocalcemia was defined as corrected calcium $<2.11 \mathrm{mmol} / \mathrm{L}$, and patients were further grouped into normal calcium group and hypocalcemia group.

Moreover, we collected the requirement of blood transfusion and transfusion volume from medical records. Blood transfusion at our institution was performed only when an absolute $\mathrm{Hb}<80 \mathrm{~g} / \mathrm{L}$ independent of signs or symptoms of anemia, or $\mathrm{Hb}<90 \mathrm{~g} / \mathrm{L}$ for symptomatic patients (extreme weakness, chest pain, extreme paleness, or major bleeding) with destabilizing vital signs (heart rate $>100$ beats/min or systolic blood pressure $<90 \mathrm{mmHg}$ ).

\section{Total blood loss calculation}

The patient blood volume (BV) was estimated according to the Nadler formula [29]: BV (L) for men=height $(\mathrm{m}) 3 \times 0.367$ + weight $\quad(\mathrm{Kg}) \times 0.032+0.604, \quad$ BV (L) for women $=$ height $(\mathrm{m})^{3} \times 0.356+$ weight $(\mathrm{Kg}) \times 0.033+0.183$. The total blood loss $(\mathrm{TBL})$ was calculated according to the Gross formula [30]: TBL $(\mathrm{ml})=\mathrm{BV}(\mathrm{L}) \times\left(\mathrm{Hct}_{\mathrm{adm}}-\mathrm{Hct}_{\text {post }}\right) / \mathrm{Hct}_{\text {ave }} \times 1000$, where Hct $_{\text {adm }}$ is the initial admission Hct, Hct post $_{\text {is Hct within }}$ 3 days after surgery, and Hct $\mathrm{ave}_{\text {ive }}$ is the average of Hct $\mathrm{adm}_{\mathrm{a}}$ and $\mathrm{Hct}_{\text {post }}$. When transfusion was performed from the time of admission to the data of postoperative blood routine test, $\mathrm{TBL}(\mathrm{ml})=\mathrm{BV}(\mathrm{L}) \times\left(\mathrm{Hct}_{\mathrm{adm}}-\mathrm{Hct}_{\text {post }}\right) /$ 
Elderly patients with hip

fracture in the database

$$
(n=1044)
$$

Exclusions:

1. Non-surgical treatment

$(n=327)$

2. No blood routine test within postoperative 3 days $(n=115)$

3. No admission calcium, $\mathrm{Hb}$, Hct data $(n=19)$

Elderly patients with hip

fracture in the final analysis

$$
(n=583)
$$
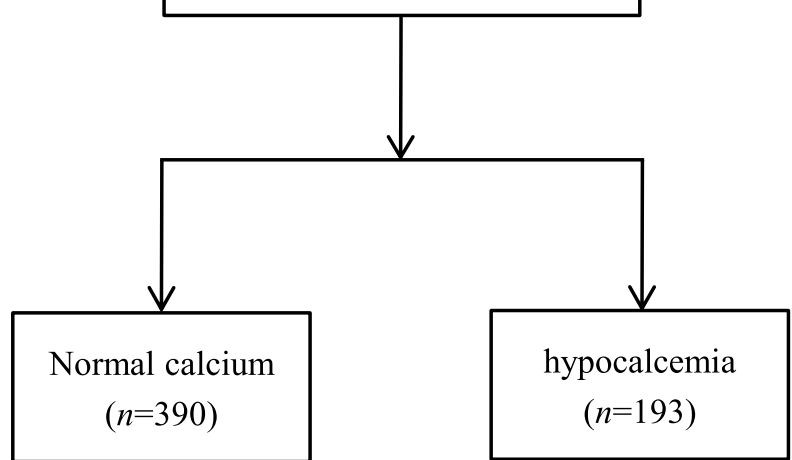

Fig. 1 Flow chart of patient inclusion

Hct $_{\text {ave }} \times 1000+$ blood transfusion $(\mathrm{ml})$. A unit of red blood cell transfusion is approximately $200 \mathrm{ml}$.

\section{Statistical analysis}

Continuous variables were described as mean \pm standard deviation (SD), and analyzed with Student's t-test, while categorical variables were expressed as frequency (percentage), and compared with the chi-squared test. Linear regression analysis was used to test the correlation of various clinical factors with perioperative total blood loss. Variables with $P<0.1$ were included in multivariate linear regression analysis to identify the independent risk factors associated with total blood loss. All reported $P$ values are two-sided, and $P<0.05$ were considered statistically significant. All analyses were performed using JMP Pro software (version 16.0; SAS Institute Inc., Cary, NC, USA).

\section{Results}

\section{Patient characteristics}

A total of 583 consecutive elderly patients with hip fracture were included in this study. The baseline characteristics are shown in Table 1. On admission, the mean corrected calcium was $2.17 \pm 0.14 \mathrm{mmol} / \mathrm{L}$, and the prevalence of hypocalcemia was $33.11 \%$ (95\% CI: $29.42-$ 37.02). When comparing patients with normal calcium, hypocalcemia patients had a higher incidence of anemia (79.79\% vs $67.95 \%, P<0.05)$. Apart from this, no significant differences were observed between the two groups.

\section{Perioperative blood loss}

The perioperative $\mathrm{Hb}$, Hct, transfusion and blood loss data are presented in Table 2. There were significant differences in admission and postoperative $\mathrm{Hb}$ and Hct levels between the two groups $(P<0.05)$. Moreover, the drop in $\mathrm{Hb}$ for hypocalcemia and normal calcium patients were $17.25 \pm 15.16 \mathrm{~g} / \mathrm{L}$ and $12.24 \pm 17.39 \mathrm{~g} / \mathrm{L}$, and the difference was statistically significant $(P<0.05)$. Likewise, the difference in Hct was significantly larger in hypocalcemia group compared with normal calcium group $(5.22 \pm 4.52 \%$ vs $3.72 \pm 5.40 \%, P<0.05)$. Also, the blood transfusion rate in hypocalcemia group was higher than normal calcium group $(16.06 \%$ vs $7.69 \%, P<0.05)$, but transfusion volume difference did not reach significance $(P=0.533)$. The mean total blood loss for hypocalcemia group was $719.18 \pm 569.98 \mathrm{ml}$, which was significantly 
Table 1 Baseline characteristics according to serum calcium

\begin{tabular}{|c|c|c|c|}
\hline Variables & Normal calcium $(n=390)$ & Hypocalcemia $(n=193)$ & Pvalue \\
\hline Age (years) & $78.96 \pm 8.45$ & $80.04 \pm 7.59$ & 0.135 \\
\hline Sex, n (\%) & & & 0.076 \\
\hline Male & $113(28.97)$ & $70(36.27)$ & \\
\hline Female & $277(71.03)$ & $123(63.73)$ & \\
\hline Height (cm) & $157.44 \pm 6.59$ & $158.11 \pm 6.15$ & 0.243 \\
\hline Weight (Kg) & $54.00 \pm 8.97$ & $53.87 \pm 6.98$ & 0.861 \\
\hline $\mathrm{BMI}\left(\mathrm{Kg} / \mathrm{m}^{2}\right)$ & $21.72 \pm 2.90$ & $21.51 \pm 2.18$ & 0.372 \\
\hline Hypertension, n (\%) & $142(36.41)$ & $67(34.72)$ & 0.688 \\
\hline Diabetes mellitus, n (\%) & $70(17.95)$ & $40(20.73)$ & 0.423 \\
\hline Anemia on admission, $\mathrm{n}(\%)$ & $265(67.95)$ & $154(79.79)$ & 0.002 \\
\hline CCl score, n (\%) & & & 0.377 \\
\hline None & $213(54.62)$ & $99(51.30)$ & \\
\hline Low & $120(30.77)$ & $57(29.53)$ & \\
\hline Moderate/severe & $57(14.62)$ & $37(19.17)$ & \\
\hline Time from injury to hospital (h) & $9.5(3.0,48.0)$ & $10.0(2.0,72.0)$ & 0.624 \\
\hline Hip fracture type, n (\%) & & & 0.769 \\
\hline Femoral neck & $195(50.00)$ & $94(48.70)$ & \\
\hline Intertrochanteric & $195(50.00)$ & $99(51.30)$ & \\
\hline
\end{tabular}

Abbreviations: $B M I$ Body mass index, $\mathrm{CCl}$ Charlson comorbidity index

Table 2 Perioperative hemoglobin, hematocrit, transfusion and blood loss according to serum calcium

\begin{tabular}{llll}
\hline Variables & Normal calcium $(\boldsymbol{n = 3 9 0 )}$ & Hypocalcemia $(\boldsymbol{n}=\mathbf{1 9 3})$ & $\boldsymbol{P}$ value \\
\hline $\begin{array}{l}\text { Blood volume }(\mathrm{L}) \\
\mathrm{Hb}(\mathrm{g} / \mathrm{L})\end{array}$ & $3.48 \pm 0.55$ & $3.52 \pm 0.53$ & 0.373 \\
$\quad$ Admission & $113.25 \pm 18.58$ & $103.92 \pm 20.22$ & $<0.001$ \\
$\quad$ Postoperative & $101.01 \pm 16.82$ & $86.67 \pm 15.99$ & 0.003 \\
$\triangle \mathrm{Hb}$ & $12.24 \pm 17.39$ & $17.25 \pm 15.16$ & $<0.001$ \\
$\mathrm{Hct}(\%)$ & & & $<0.001$ \\
$\quad$ Admission & $35.09 \pm 5.34$ & $32.34 \pm 5.93$ & 0.004 \\
Postoperative & $31.37 \pm 5.07$ & $27.12 \pm 4.70$ & 0.001 \\
$\triangle$ Hct & $3.72 \pm 5.40$ & $5.22 \pm 4.52$ & 0.003 \\
Blood transfusion, $\mathrm{n}(\%)$ & $30(7.69)$ & $31(16.06)$ & 0.533 \\
Mean transfusion volume $(\mathrm{ml})$ & $516.67 \pm 219.85$ & $558.06 \pm 289.57$ & 0.016 \\
Mean total blood loss $(\mathrm{ml})$ & $607.86 \pm 497.07$ & $719.18 \pm 569.98$ & \\
\hline
\end{tabular}

Note: $\triangle \mathrm{Hb}, \triangle \mathrm{HCT}$ was difference from admission to postoperative

Abbreviations: $\mathrm{Hb}$ Hemoglobin, $\mathrm{Hct}$ Hematocrit

larger than normal calcium group $(607.86 \pm 497.07 \mathrm{ml}$, $P<0.05)$.

\section{Factors influencing total blood loss}

Linear regression analysis showed that BMI, anemia on admission, time from injury to hospital, hip fracture type, blood transfusion and serum calcium were associated with total blood loss (Table 3). In the multivariate linear regression analysis (Table 4), factors that were independently associated with increased total blood loss were male, anemia on admission, time from injury to hospital, intertrochanteric fracture, blood transfusion and hypocalcemia $(P<0.05)$.

\section{Discussion}

In this study, the prevalence of hypocalcemia was $33.11 \%$ in hip fracture patients, which was similar to other studies in elderly orthopedic patients [23-25]. Similarly, almost $27.72 \%$ of hospital patients may experience hypocalcemia, and the incidence was the highest in patients 
Table 3 Linear regression analysis of factors associated with total blood loss

\begin{tabular}{lll}
\hline Variable & $\mathbf{R}^{\mathbf{2}}$ & $\boldsymbol{P}$ value \\
\hline Age (years) & 0.002 & 0.237 \\
Sex & 0.005 & 0.076 \\
$\mathrm{BMI}\left(\mathrm{Kg} / \mathrm{m}^{2}\right)$ & 0.009 & 0.025 \\
Hypertension & 0.001 & 0.384 \\
Diabetes mellitus & 0.002 & 0.313 \\
Anemia on admission & 0.007 & 0.045 \\
CCl score & 0.001 & 0.662 \\
Time from injury to hospital (h) & 0.015 & 0.003 \\
Hip fracture type & 0.044 & $<0.001$ \\
Blood transfusion & 0.031 & $<0.001$ \\
Serum calcium & 0.010 & 0.016 \\
\hline
\end{tabular}

over 65 years [31]. Regarding the harm of hypocalcemia, a recent review summarized the relationships between preoperative hypocalcemia and postoperative adverse complications in elderly patients [32], and another systematic review found admission hypocalcemia was associated with increased mortality in trauma patients [18]. These findings suggest that clinicians should pay attention to hypocalcemia because of life-threatening consequence [31].

Beyond those mentioned above, serum calcium is a key component of coagulation cascade. Hence, we hypothesized that low serum calcium may led to more perioperative blood loss. As expected, we found that hypocalcemia patients had more total blood loss in elderly patients with hip fracture, along with larger differences in $\mathrm{Hb}$ and Hct levels from admission to postoperative day. Even after adjusting for potential confounding factors, hypocalcemia still played an independent role in blood loss, and led to an almost $50.338 \mathrm{ml}$ increase in total blood loss. Consistent with this finding, Morotti et al. [19] reported that the presence of hypocalcemia on admission was indeed associated with the extent of bleeding in patients with intracerebral hemorrhage. This effect was also observed in patients with postpartum hemorrhage [20], and total knee arthroplasty [23]. For this reason, trials are needed to assess whether correction of hypocalcemia will lead to decreased blood loss [20, 21].

In this study, the rate of blood transfusion was $10.46 \%$ (95\% CI: 8.23-13.21), which was lower than report of Nikolaou et al. (63.47\%) [6], Ohmori et al. (32.67\%) [33], and Guo et al. (29.7\%) [5] in hip fracture patients. The reason might be that the blood loss continue until several days after surgery [9], but this study only analyzed the blood transfusions from admission to the time of blood routine test. Consistent with the finding of total blood loss, hip fracture patients with hypocalcemia exhibited a higher blood transfusion rate, although transfusion volume difference did not reach significance. Also, trauma patients [22], and upper gastrointestinal bleeding patients [21] with hypocalcemia were most likely to receive a blood transfusion.

Moreover, we found some other factors associated with increased total blood loss, including male, time from injury to hospital, intertrochanteric fracture, and blood transfusion, which were consistent with previous studies $[5,10,11]$. In this study, anemia on admission was identified as another independent risk factor for total blood loss. Similarly, Miguel et al. [34] showed that anemia on admission was associated with more severe intracerebral hemorrhage. Also, low $\mathrm{Hb}$ level was associated with blood transfusion in elderly patients with hip fracture [13], this may be the reason for the increased total blood loss.

However, this study has some limitations. First, as this was a retrospective study, we were not able to collect sufficient information on history of osteoporosis and anti-osteoporotic agents, which may affect serum calcium level. In particular, we also did not obtain the anticoagulant and antiplatelet treatment. Yet, a recent study found antiplatelet treatment did not affect perioperative blood loss in patients with hip fracture [33]. Second, it was a single-center study, and the sample size was

Table 4 Multivariate linear regression analysis of factors associated with total blood loss

\begin{tabular}{|c|c|c|c|c|}
\hline Variable & Coefficient B & SE & $95 \% \mathrm{Cl}$ for $\mathrm{B}$ & $P$ value \\
\hline Constant & 563.362 & 178.579 & 212.615-914.109 & 0.002 \\
\hline Sex (male/female) & 53.183 & 22.211 & $9.559-96.806$ & 0.017 \\
\hline BMI $\left(\mathrm{Kg} / \mathrm{m}^{2}\right)$ & 14.083 & 7.907 & $-1.446-29.613$ & 0.075 \\
\hline Anemia on admission & 107.230 & 25.027 & $58.073-156.386$ & $<0.001$ \\
\hline Time from injury to hospital (h) & -0.552 & 0.231 & $-1.006--0.098$ & 0.017 \\
\hline Type of fracture (intertrochanteric/femoral neck) & 126.319 & 21.644 & $83.809-168.830$ & $<0.001$ \\
\hline Blood transfusion & 143.271 & 34.274 & $75.955-210.588$ & $<0.001$ \\
\hline Serum calcium (hypocalcemia/normal) & 50.338 & 22.054 & $7.022-93.655$ & 0.023 \\
\hline
\end{tabular}

Abbreviations: SE Standard error, CI Confidence interval 
small. Therefore, multi-center and larger-scale studies are needed to confirm our results. Third, we only used serum albumin corrected calcium instead of ionized calcium to evaluate the true level of calcium, which may be inaccurate in the presence of protein and $\mathrm{pH}$ imbalances. Finally, the fluid volume administered perioperatively was not controlled, and this may affect the calculation of the total blood loss. Likewise, the formula to estimate blood loss does not represent the accurate amount of blood loss [33].

\section{Conclusion}

Hypocalcemia is common in elderly patients with hip fracture, and significantly associated with more total blood loss and blood transfusion. The other risk factors for increased total blood loss are male, anemia on admission, time from injury to hospital, intertrochanteric fracture, and blood transfusion.

\section{Abbreviations \\ Hb: Hemoglobin; Hct: Hematocrit; CCl: Charlson comorbidity index; BMI: Body mass index; CT: Computed tomography; BV: Blood volume; TBL: Total blood loss; SD: Standard deviation. \\ Acknowledgements \\ We would like to thank several nurses from the Department of Orthopedic Surgery in Deyang People's Hospital, for the help with the data inspection.}

\section{Authors' contributions}

Zhicong Wang: Conceptualization, Methodology, Formal analysis, Software, Visualization, Funding acquisition, Writing-original draft, Project administration. Xi Chen: Methodology, Formal analysis, Writing-review \& editing, Project administration. Yan Chen: Methodology, Formal analysis, Writing-review \& editing, Project administration. Ling Yang: Conceptualization, Funding acquisition, Investigation, Supervision, Validation. Hong Wang: Conceptualization, Investigation, Supervision, Validation. Wei Jiang: Conceptualization, Investigation, Supervision, Validation. Shuping Liu: Conceptualization, Methodology, Writingreview \& editing, Project administration, Supervision, Validation. All authors read and approved the final manuscript. Yuehong Liu: Conceptualization, Methodology, Writing-review \& editing, Project administration, Supervision, Validation. All authors read and approved the final manuscript.

\section{Funding}

This study was supported by Sichuan Science and Technology Program (No. 2021JDR0337), and Deyang Science and Technology Bureau Project (No. 2019SZ125).

\section{Availability of data and materials}

The data used during the current study are available from the corresponding author on reasonable request.

\section{Declarations}

\section{Ethics approval and consent to participate}

The study protocol was approved by the Institutional Ethics Committee at Deyang People's Hospital (IRD number 2021-04-019-K01). Permission to waive the informed consent was obtained from the institutional review board for this observational retrospective study. This study was performed in accordance with the ethical standards in the 1964 Declaration of Helsinki.

\section{Consent for publication}

Not applicable.

\section{Competing interests}

The authors declare that they have no competing interests.

Received: 7 July 2021 Accepted: 26 November 2021

Published online: 07 December 2021

\section{References}

1. Zhang C, Feng J, Wang S, Gao P, Xu L, Zhu J, et al. Incidence of and trends in hip fracture among adults in urban China: A nationwide retrospective cohort study. PLoS Med. 2020;17(8):e1003180.

2. Shigemoto K, Sawaguchi T, Horii T, Goshima K, Iwai S, Higashikawa T, et al. Multidisciplinary care model for geriatric patients with hip fracture in Japan: 5-year experience. Arch Orthop Trauma Surg. 2021. https://doi. org/10.1007/s00402-021-03933-w.

3. Gong X, Li X, Zhang L, Center J, Bliuc D, Shi Y, et al. Current status and distribution of hip fractures among older adults in China. Osteoporos Int. 2021. https://doi.org/10.1007/s00198-021-05849-y.

4. Veronese N, Maggi S. Epidemiology and social costs of hip fracture. Injury. 2018;49(8):1458-60.

5. Guo W, Wang J, Zhang W, Wang W, Xu D, Luo P. Hidden blood loss and its risk factors after hip hemiarthroplasty for displaced femoral neck fractures: a cross-sectional study. Clin Interv Aging. 2018;13:1639-45.

6. Nikolaou V, Masouros P, Floros T, Chronopoulos E, Skertsou M, Babis G. Single dose of tranexamic acid effectively reduces blood loss and transfusion rates in elderly patients undergoing surgery for hip fracture: a randomized controlled trial. Bone Joint J. 2021:3:442-8.

7. Xu K, Anwaier D, He R, Zhang X, Qin S, Wang G, et al. Hidden blood loss after hip hemiarthroplasty using the superPATH approach: A retrospective study. Injury. 2019;50(12):2282-6.

8. Tian S, Li H, Liu M, Zhang Y, Peng A. Dynamic analysis of perioperative hidden blood loss in intertrochanteric fractures. Clin Appl Thromb Hemost. 2019;25:1076029618823279.

9. Luo X, He S, Li Z, Li Q. Quantification and influencing factors of perioperative hidden blood loss during intramedullary fixation for intertrochanteric fractures in the elderly. Arch Orthop Trauma Surg. 2020;140(10):1339-48.

10. Tüzün H, Bilekli A, Erşen Ö. The factors that affect blood loss in intertrochanteric fractures treated with proximal femoral nail in the elderly. Eur J Trauma Emerg Surg. 2021. https://doi.org/10.1007/s00068-021-01670-8.

11. Guo J, Zhang Y, Hou Z. Intramedullary fixation does not cause a large amount of hidden blood loss in elderly patients with intertrochanteric fractures. Clin Interv Aging. 2021;16:475-86.

12. Wu J, Liu P, Ge W, Cai M. A prospective study about the preoperative total blood loss in older people with hip fracture. Clin Interv Aging. 2016;11:1539-43.

13. Yombi J, Putineanu D, Cornu O, Lavand'homme P, Cornette P, CastanaresZapatero D. Low haemoglobin at admission is associated with mortality after hip fractures in elderly patients. Bone Joint J. 2019;9:1122-8.

14. Zhang Z, Pereira S, Luo M, Matheson E. Evaluation of blood biomarkers associated with risk of malnutrition in older adults: A systematic review and Meta-analysis. Nutrients. 2017;9(8). https://doi.org/10.3390/nu908 0829

15. Endres $H$, Wedding U, Pittrow D, Thiem U, Trampisch H, Diehm C. Prevalence of anemia in elderly patients in primary care: impact on 5-year mortality risk and differences between men and women. Curr Med Res Opin. 2009;25(5):1143-58.

16. Boureau A, de Decker L. Blood transfusion in older patients. Transfus Clin Biol. 2019;26(3):160-3.

17. Wray J, Bridwell R, Schauer S, Shackelford S, Bebarta V, Wright F, et al. The diamond of death: Hypocalcemia in trauma and resuscitation. Am J Emerg Med. 2021;41:104-9.

18. Vasudeva M, Mathew J, Groombridge C, Tee J, Johnny C, Maini A, et al. Hypocalcemia in trauma patients: A systematic review. J Trauma Acute Care Surg. 2021;90(2):396-402.

19. Morotti A, Charidimou A, Phuah C, Jessel M, Schwab K, Ayres A, et al. Association between serum calcium level and extent of bleeding in patients with Intracerebral hemorrhage. JAMA Neurol. 2016;73(11):1285-90.

20. Epstein D, Solomon N, Korytny A, Marcusohn E, Freund Y, Avrahami $R$, et al. Association between ionised calcium and severity of 
postpartum haemorrhage: a retrospective cohort study. $\mathrm{Br} J$ Anaesth. 2021;126(5):1022-8.

21. Korytny A, Klein A, Marcusohn E, Freund Y, Neuberger A, Raz A, et al. Hypocalcemia is associated with adverse clinical course in patients with upper gastrointestinal bleeding. Intern Emerg Med. 2021. https://doi.org/ 10.1007/s11739-021-02671-6.

22. Vasudeva M, Mathew J, Fitzgerald M, Cheung Z, Mitra B. Hypocalcaemia and traumatic coagulopathy: an observational analysis. Vox Sang. 2020;115(2):189-95.

23. Gai P, Sun H, Sui L, Wang G. Hypocalcaemia after Total knee Arthroplasty and its clinical significance. Anticancer Res. 2016;36(3):1309-11.

24. Wang $L, X u$ D, Wei $X$, Chang $H$, Xu G. Electrolyte disorders and aging: risk factors for delirium in patients undergoing orthopedic surgeries. BMC Psychiatry. 2016;16(1):418.

25. Mao Y, Zheng Y, Li Y, Wang G, Sun J, Cui X. Factors associated with perioperative serum calcium levels in percutaneous Kyphoplasty for osteoporotic vertebral compression fracture: A prospective clinical study. Med Sci Monit. 2019;25:1800-5.

26. Wang Z, Jiang W, Chen X, Yang L, Wang H, Liu Y. Systemic immune-inflammation index independently predicts poor survival of older adults with hip fracture: a prospective cohort study. BMC Geriatr. 2021;21(1):155.

27. Riska L, B, Forsén L, Omsland T, Søgaard A, Meyer H, Holvik K. Does the Association of Comorbidity with 1-year mortality after hip fracture differ according to gender? The Norwegian epidemiologic osteoporosis studies (NOREPOS). J Am Geriatr Soc. 2018;66(3):553-8.

28. Pepe J, Colangelo L, Biamonte F, Sonato C, Danese V, Cecchetti $\checkmark$, et al. Diagnosis and management of hypocalcemia. Endocrine. 2020;69(3):485-95.

29. Nadler S, Hidalgo J, Bloch T. Prediction of blood volume in normal human adults. Surgery. 1962;51(2):224-32.

30. Gross J. Estimating allowable blood loss: corrected for dilution. Anesthesiology. 1983;58(3):277-80.

31. Catalano A, Chilà D, Bellone F, Nicocia G, Martino G, Loddo I, et al. Incidence of hypocalcemia and hypercalcemia in hospitalized patients: is it changing? J Clin Transl Endocrinol. 2018;13:9-13.

32. Lee K, Lee I. Preoperative laboratory testing in elderly patients. Curr Opin Anaesthesiol. 2021;34(4):409-14.

33. Ohmori T, Toda K, Kanazawa T, Tada K, Yagata Y, Ito Y. Retrospective high volume comparative study suggests that patients on aspirin could have immediate surgery for hip fractures without significant blood loss. Int Orthop. 2021;45(3):543-9.

34. Bussière M, Gupta M, Sharma M, Dowlatshahi D, Fang J, Dhar R. Anaemia on admission is associated with more severe intracerebral haemorrhage and worse outcomes. Int J Stroke. 2015;10(3):382-7.

\section{Publisher's Note}

Springer Nature remains neutral with regard to jurisdictional claims in published maps and institutional affiliations.

Ready to submit your research? Choose BMC and benefit from:

- fast, convenient online submission

- thorough peer review by experienced researchers in your field

- rapid publication on acceptance

- support for research data, including large and complex data types

- gold Open Access which fosters wider collaboration and increased citations

- maximum visibility for your research: over $100 \mathrm{M}$ website views per year

At $\mathrm{BMC}$, research is always in progress.

Learn more biomedcentral.com/submissions 